\title{
Micronodular adrenal disease: a light and electron microscopic study
}

\author{
PS HASLETON, HH ALI, C ANFIELD, CG BEARDWELL, S SHALET \\ From the Departments of Pathology and Endocrinology, Withington Hospital, Manchester
}

\begin{abstract}
SUMMARY A case of Cushing's syndrome due to micronodular adrenal disease in a 17-year-old girl is presented. The adrenals showed both black and yellow nodules. Histologically the cells contained lipofuschin and either had a clear cytoplasm or an eosinophilic cytoplasm with a prominent nucleus. Lymphocytes were a prominent feature. No cells of the zona reticularis were identified. The cell of origin of these nodules appeared to be from the inner layer of the zona fasciculata. We postulate that the disease is caused by an abnormality in the migration and ultimate destruction of cells from the zona fasciculata to the zona reticularis with a build up of cells at the interface zone.
\end{abstract}

Micronodular adrenal disease (primary adrenal cortical dysplasia) is an uncommon cause of Cushing's syndrome. In a recent monograph on adrenal disease $^{1}$ micronodular disease is not mentioned. Previous reports accurately describe the macroscopic and light microscopic features but are unclear as to the origin of the cells in the nodules. We describe below a case of primary adrenal cortical dysplasia with electron microscopic findings to determine the cell type responsible for the adrenal nodule formation.

\section{Case report}

A 17-year-old girl was admitted to hospital because of hirsuitism and secondary amenorrhoea. Her early growth and development had been normal. Menarche occurred at the age of 12 but periods stopped one year later at which time she developed the classical features of Cushing's syndrome which progressed steadily over the next four years. Biochemical investigations showed a greatly raised basal 24-hour urinary excretion of 11hydroxycorticosteroids, 17-oxogenic steroids and 17-oxosteroids with an absent diurnal variation of plasma cortisol, thus confirming the clinical diagnosis of Cushing's syndrome.

The plasma ACTH level was undetectable on several occasions and the urinary excretion of 17oxogenic steroids was unaltered by either metyrapone or dexamethasone administration.

An $x$-ray examination of the pituitary fossa, dorsal and lumbar spine was completely normal. Abdominal

Accepted for publication 8 February 1982
CT scan showed that the right adrenal gland appeared larger than the left adrenal gland. Scintigraphy with radioisotope-labelled cholesterol showed uptake only in the region of the right adrenal. In view of the radiological and biochemical findings it was thought that she had a right-sided adrenal tumour. A right adrenalectomy was performed. The gland appeared normal in size and showed many micronodules but no adenoma. The provisional diagnosis was revised to that of micronodular adrenal disease and since this is usually bilateral, it was thought advisable to remove the remaining adrenal. After the second operation the clinical features of Cushing's syndrome resolved and regular menses returned.

\section{PATHOLOGY}

The right adrenal weighed $8 \cdot 2 \mathrm{~g}$, the left $5 \cdot 3 \mathrm{~g}$. The appearance of both glands was similar. There were numerous nodules, some black and others yellow set in a yellow cortex. The largest nodule measured $1 \times 0.5 \mathrm{~cm}$. The right adrenal was fixed in Carson's fluid. Small blocks $\left(1 \mathrm{~mm}^{3}\right)$ were taken from the left adrenal and fixed in 4\% glutaraldehyde in Sorenson's phosphate buffer at $4^{\circ} \mathrm{C}$. The blocks were post-fixed in $1 \%$ phosphate-buffered osmium tetroxide. The material was embedded in Epon resin. Sections (1 $\mu \mathrm{m})$ were cut and stained with toluidine blue. Thin sections were cut on an LKB IV ultramicrotome, stained with uranyl acetate and lead citrate and examined on an AEI EM810 electron microscope.

Blocks from the right adrenal were first washed in cacodylate buffer, post-fixed in osmium tetroxide and embedded in Epon resin as above. Blocks were taken from both the yellow and black areas.

On light microscopy the presence of nodularity 


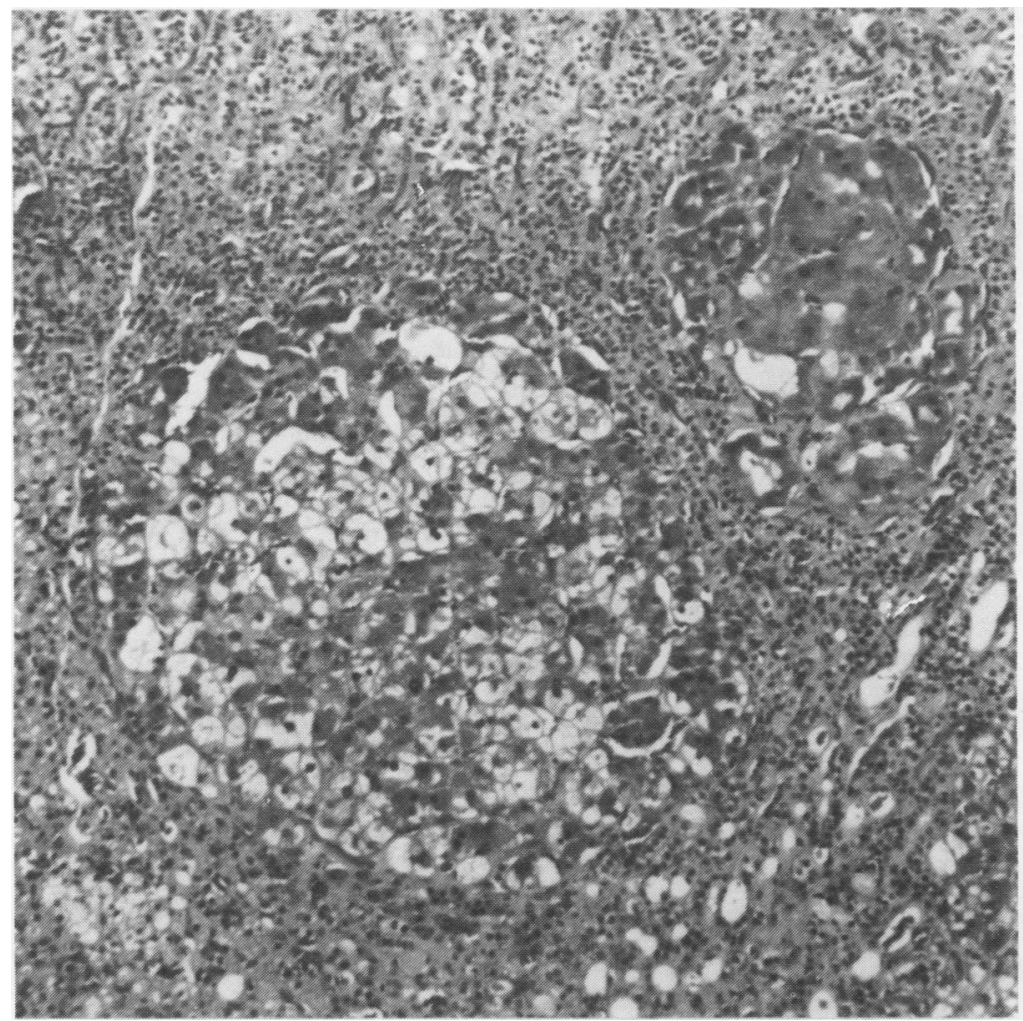

Fig. 1 Low power photomicrograph showing the typical nodular appearance of the adrenal. Haematoxylin and eosin $\times$ 120.

was confirmed (Fig. 1). The zona glomerulosa was compressed in areas but in other fields it dipped down between the nodules and appeared thicker than normal. The zona fasciculata was sparse but groups of cells with a clear cytoplasm lying outside the nodules were identified. No cells from the zona reticularis were found in the non-nodular adrenal tissue.

The nodules which were of two types composed the majority of the adrenal glands. The most prominent type of nodule consisted of large cells with an eosinophilic cytoplasm, a large nucleus that was either open and vesicular or pyknotic (Fig. 2). Other nodules consisted of large clear cells. Some of the nodules consisted of both clear and eosinophilic cells. The reticulin stain showed the nodular pattern well. The eosinophilic cells contained a dark brown pigment that was not haemosiderin or melanin but stained positively with a prolonged Ziehl-Neelsen stain proving the presence of lipofuschin. Between the nodules were many dilated capillaries. Some nodules were present outside the capsule, in the periadrenal fat.

In relation to some nodules were foci of lymphocytes (Fig. 2). The cells showed no evidence of necrosis in these areas and no giant cells were seen.
Prominent phaeochromocytes were present, sometimes as isolated cells but otherwise the medulla was normal. Ganglion cells were seen in the adrenal fat, in the capsule and inside the cortex in one instance. Hypertensive arterioles were present in the periadrenal fat.

\section{ELECTRON MICROSCOPY}

Blocks were taken from both black and yellow foci. The cells had microvilli, a convoluted plasma membrane and large prominent mitochondria. The mitochondria had a tubulovesicular internal structure (Fig. 3). Many dense black homogeneous lysosomes were present (Fig. 4). In some cells the mitochondria had a mixture of dark and pale circular areas as well as lamellar structures inside them. Such mitochondria may be undergoing lysis. Myelin figures were also seen (Fig. 5). Many free and membrane-attached ribosomes were present. Foci of black material, not bound by any membrane, were present. In other cells the lipid had dissolved out leaving clear foci. Rough endoplasmic reticulum was present in many areas forming parallel stacks. The nuclei had small indentations but were otherwise unremarkable. Such cells are typical of the interface region of the zona fasciculata. 


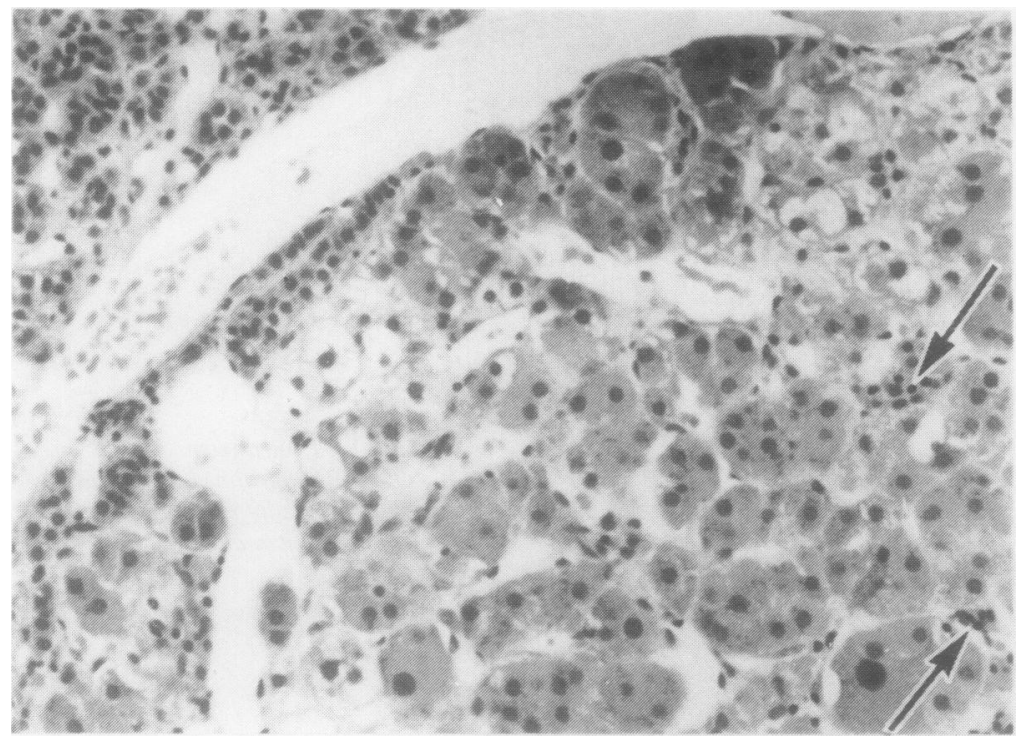

Fig. 2 Part of a nodule with the zona glomerulosa in the top left hand corner. Most of the cells have an eosinophilic cytoplasm though cells with a clear cytoplasm are present. Foci of lymphocytes (arrows) are present. Haematoxylin and eosin $\times 211$.

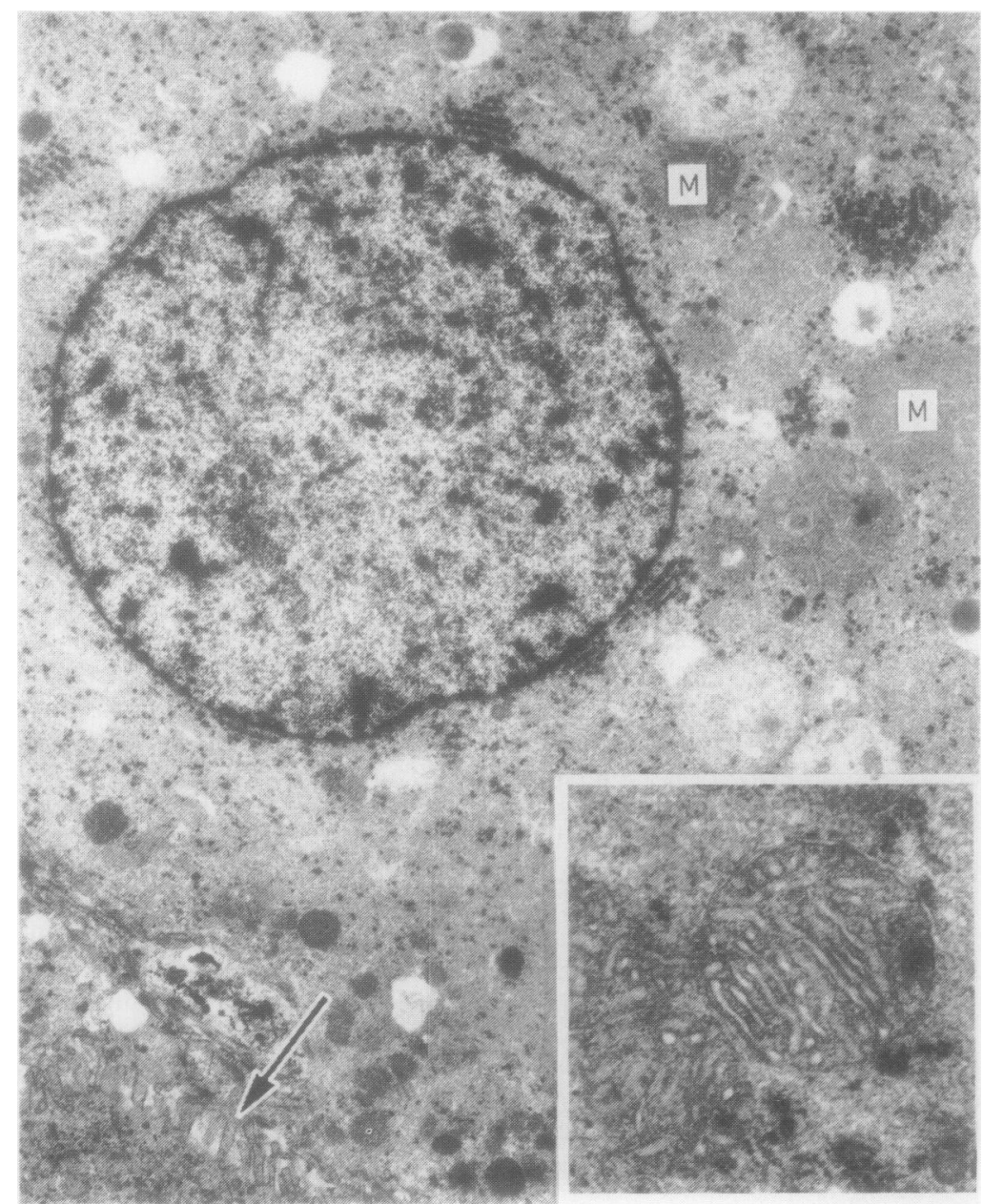

Fig. 3 Cell of inner zona fasciculata with numerous mitochondria $(M)$, microvilli (arrow). Uranyl acetate and lead citrate $\times 7000$. The inset shows mitochondria with a tubulovesicular internal structure. Uranyl acetate and lead citrate $\times 28800$. 


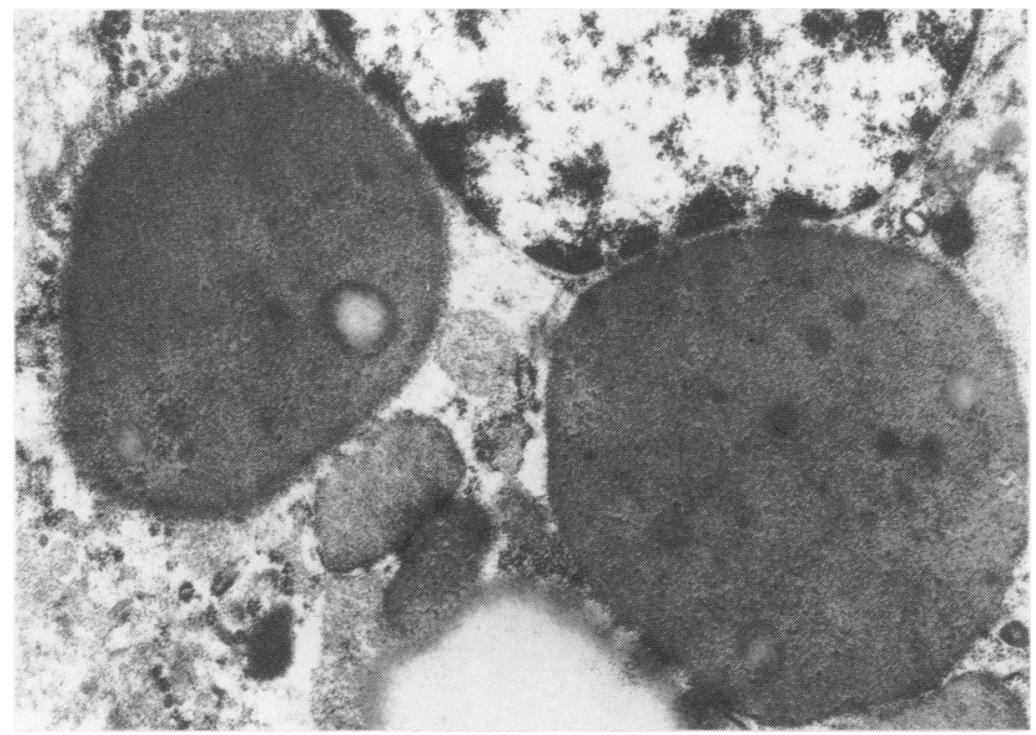

Fig. 4 Area from a black nodule showing dense lysosomes abutting a nucleus. Uranyl acetate and lead citrate $\times 20000$.

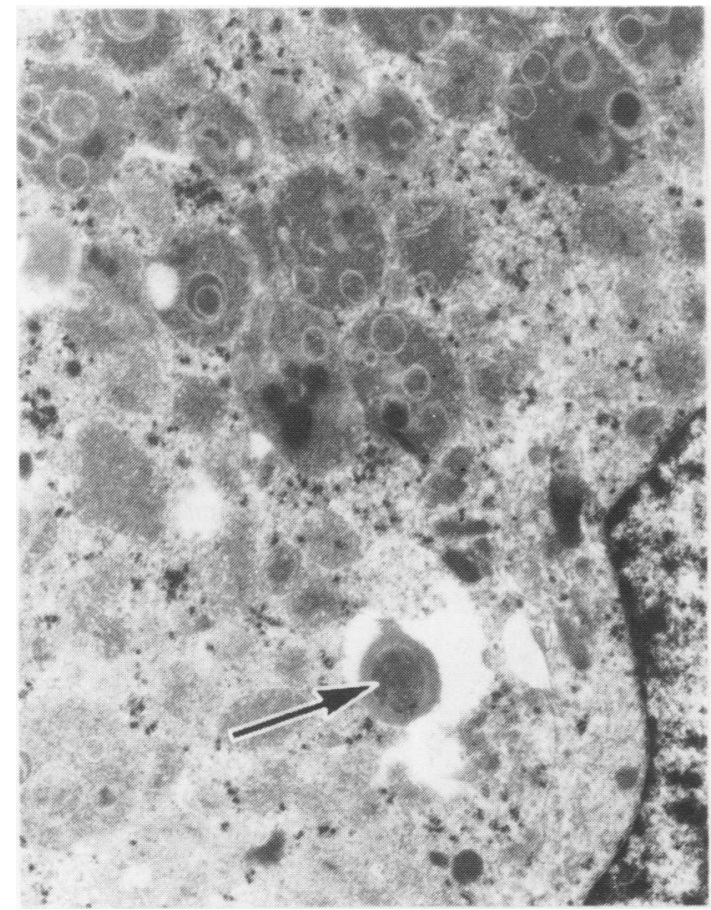

Fig. 5 Mitochondria with both dark and pale circular areas as well as a myelin figure (arrow). Uranyl acetate and lead citrate $\times 12600$. 


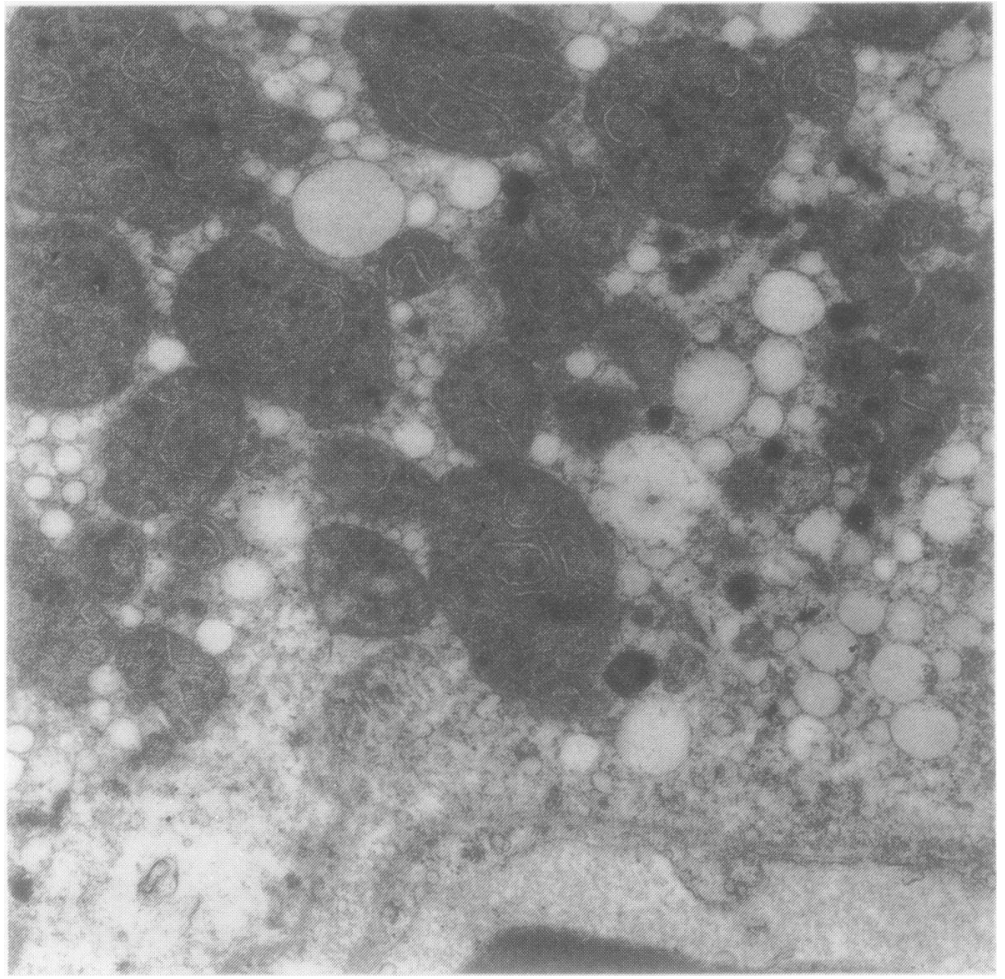

Fig. 6 Part of a cell from a yellow nodule with many mitochondria and much lipid. Uranyl acetate and lead citrate $\times 18500$.

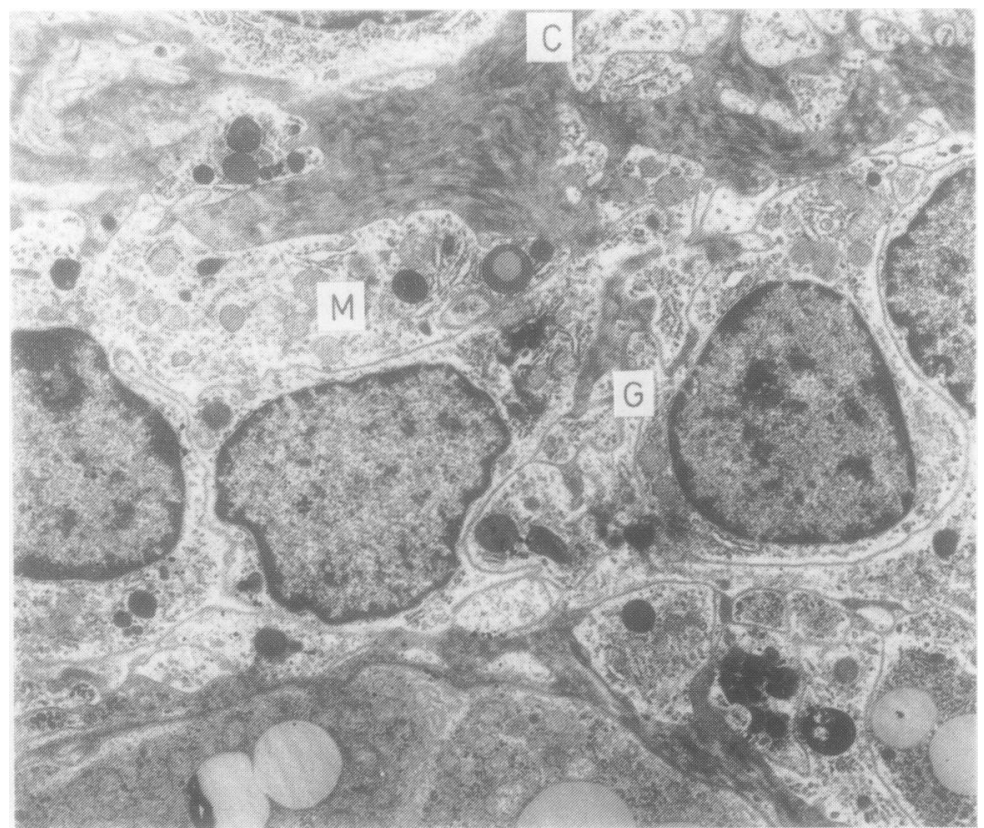

Fig. 7 Cells of the zona glomerulosa $(G)$ with a large nucleus, regular cell border and few mitochondria $(M)$. The capsule $(C)$ is seen at the top of the picture. Uranyl acetate and lead citrate $\times$ 5000. 
Blocks from the yellow nodules showed a similar appearance to the black areas but there were more clear foci, some of which presumably represented fat that had dissolved out (Fig. 6). Other areas were probably endoplasmic reticulum. The mitochondria were prominent and these also had a tubulovesicular internal structure. Thus these cells also showed the characteristics of the zona fasciculata from the interface zone.

Cells of the zona glomerulosa were identified (Fig. 7) with a larger nuclear/cytoplasmic ratio than the cells in the zona fasciculata. The basement membrane was not crenated. Mitochondria had a regular cristate internal structure and the cells contained osmiophilic lipid. Few lysosomes were present.

No cells from the zona reticularis were seen either inside or outside the nodules.

\section{Discussion}

Cushing's syndrome is caused by iatrogenic administration of steroids, pituitary or adrenal diseases, or less commonly, is due to ectopic secretion of ACTH by non-endocrine tumours. In this patient all the biochemical and radiological findings suggested an adrenal origin.

Histologically the appearance was typical of micronodular adrenal disease. There were nodules of varying sizes. The nodules consisted either of large clear cells or of cells having an eosinophilic cytoplasm with a dark brown pigment. Lymphocytes were prominent in areas.

The histological picture has been described previously. ${ }^{2,3}$ Characteristically, both adrenals are involved though it should be noted that usually the adrenal is normal in weight. The upper limit of the normal surgically resected adrenal is $4 \mathrm{~g}$ with an SD of $0.80 \mathrm{~g}$. ${ }^{4}$ In our case both adrenals were heavier than normal, the right gland weighing $8.2 \mathrm{~g}$ and the left $5 \cdot 3 \mathrm{~g}$. In Meador's case ${ }^{2}$ the combined weight was $9 \cdot 5 \mathrm{~g}$. Ruder described two cases. ${ }^{3}$ In case 1 the left gland weighed $3.5 \mathrm{~g}$ and the combined weight in case 2 was $4.0 \mathrm{~g}$, the right adrenal weighing only $0.9 \mathrm{~g}$.

Characteristically, the disease affects children in the second decade of life, the age range in Ruder's series being 14-37 yr. Females tend to be affected more commonly than males in a ratio of $3: 1$ as determined from the cases quoted by Ruder. ${ }^{3}$ One case of an infant presenting soon after birth with micronodular adrenal disease has been described. ${ }^{5}$ Two cases of familial Cushing's syndrome have been documented. ${ }^{6}$ However, though the adrenals had numerous micronodules in Klevit's case ${ }^{5}$, there is no description in the paper of either a black colouration of the adrenal or evidence of many lysosomes on electron microscopy. Similarly, in the case reported by Donaldson $e t a l^{\mathbf{b}}$ there is no illustration of the histology or electron microscopy. We query, therefore, whether this is the same disease entity as we are describing. The brother of our case was investigated for Cushing's syndrome as he was obese. However, there was no biochemical or sound clinical evidence of Cushing's syndrome.

In the previous studies there has been a lack of agreement as to the origin of cells in the nodules. Meador et $a l^{2}$ thought the cells were derived from zona reticularis as they were separated from the capsule by well defined fasciculata and glomerulosa layers. Ruder ${ }^{3}$ stated that the zone of origin of the nodules was unclear. In order to clarify this point we undertook electron microscopy from both yellow and black adrenal tissue.

The cells were arranged in groups and had microvilli, a convoluted plasma membrane and prominent large tubulovesicular mitochondria. Many lysosomes were present in the cytoplasm of the cell. These features are those of the zona fasciculata occuring at the interface $z^{7} e^{7}$ with the zona reticularis. The zona glomerulosa has no microvilli and in the zona reticularis microvilli are patchy. Similarly, the mitochondria in the glomerulosa, though numerous, have regular cristae and the mitochondria in the reticularis have an empty appearance with a few peripheral tubules. Lipid vacuoles were present in some cells and such material is not usually present in the zona reticularis. Mitochondrial granules are frequent in this case and are characteristic of the interface zone of the zona fasciculata. Such granules are present in the zona reticularis but are fewer in number than in the fasciculata. It is of interest that the interface zone of the zona fasciculata is the area of the adrenal believed to be the target site for the early action of ACTH. ${ }^{\text {? }}$

A constant feature of micronodular adrenal disease is the presence of many lysosomes. These interrelated membrane-limited elements form an intracellular digestive system for cells. They degrade both intracellular and extracellular substances. Symington ${ }^{7}$ felt it was probable that pigment dissolved in the lipid store of clear cells ultimately ended up in a residual body derived from lysosomes.

The tubulovesicular appearance of the mitochondria seen in our case is nearly always seen in cells producing steroids. ${ }^{7}$ It has been suggested that the vesicles are discharged either into the cytoplasm of the cell $^{8}$ or open onto the mitochondrial surface to discharge their contents-for example, corticosterone or cortisol. The dense granules in the mitochondria are possibly the site of calcium or other ion accumulation. The exact role of calcium in steroid synthesis is not known. 
The fact that the zona fasciculata is the abnormal zone in micronodular adrenal disease fits with current concepts of glucocorticoids being produced by the two inner zones of the adrenal cortex. It is thought that the zona reticularis and fasciculata are a single functional zone with the fasciculata comprising a ready reserve capable of being activated into steroid production.

In the above case there was little difference electron microscopically between the yellow and black nodules, the former having more clear spaces which contained lipid.

The final question is what is the aetiology of the condition? Meador et $a l^{2}$ suggested that it might result either from long continued ACTH overproduction or from a primary adrenal disorder. The former seems unlikely for several reasons. Most cases of micronodular dysplasia present in the second decade of life while some are certainly congenital. Thus the age distribution is quite different from Cushing's syndrome secondary to ACTH hypersecretion of pituitary or ectopic origin. In our case, as in all the others where the measurement has been made, ACTH was undetectable in the patient's serum and neither metyrapone nor dexamethasone altered steroid secretion, results indicating complete adrenal autonomy. There is no doubt that nodularity can develop in bilaterally hyperplastic adrenals associated with prolonged, excessive ACTH secretion, and it is possible that some of these nodules could eventually become autonomous and lead to partial or complete pituitary suppression. ${ }^{9}$ However, it would seem likely that this is a different condition from that described above with a different histological picture of nodules occurring in a hyperplastic cortex and, usually, considerable adrenal enlargement and a different pattern of biochemical tests. In micronodular dysplasia both adrenals are usually of normal or only slightly increased weight.

An intriguing feature of the present study is the absence of zona reticularis cells both from the nodular and the non-nodular areas of the adrenal. Though there is obviously a large sampling error, no such cells were seen on electron microscopy. This, we feel, must have some bearing on the aetiology of the disease. It has been proposed that the adrenocortical cells arise at the periphery, migrate towards the centre and die at the border with the zona reticularis and medulla. ${ }^{10}$

Wright ${ }^{11}$ studying the prepubertal rat, which has a histological picture similar to the human, also felt that there was an inward migration of cells originating in the outer regions of the cortex. He used labelling indices and studied the lengths of various components of the cell cycle in prepubertal rat adrenals. It is interesting in the present study that there are many lysosomes in the nodules. Lysosomal enzymes are important in intracellular degradation. Of further interest is the fact that some authors have used the presence of lipofuschin pigment as an indication of senescence in cells. ${ }^{12}$ Certainly in other parts of the body, such as heart and liver, the presence of lipofuschin is associated with cells showing regressive change such as atrophy accompanying old age or chronic injury. This may be taken as further proof that the elderly cells come to reside at the border of the zona fasciculata and reticularis.

Similarly, centripetal flow of cells has been proposed to explain regeneration after enucleation of the gland. ${ }^{13}$ However, most authors believe that the zona glomerulosa is independent of pituitary control while the two inner zones depend on ACTH.

In conclusion, part of the aetiology of nodular adrenal disease could be explained on the centripetal flow theory. ${ }^{11}$ If the adrenal cells migrate centrally there must be some block in the development into the zona reticularis. This will lead to a build up of cells at the interface zone which form nodules. These cells at the interface zone of the fasciculata with the reticularis normally are capable of secreting both androgens and corticosteroids and thus behave functionally in a similar way to the zona reticularis. However, in micronodular adrenal disease, there is a further change in that the accumulating cells also lose their dependence on ACTH stimulation and develop autonomous function. As a result it seems likely that they will produce cortisol continuously whereas the normal adrenal is active only intermittently. This may explain why adrenals of almost normal weight are able to produce abnormally large amounts of cortisol. The fundamental cause of these changes, though, remains unknown.

\section{References}

1 James VHT. The adrenal gland. New York:Raven Press, 1979.

${ }^{2}$ Meador CK, Bowdoin B, Crawford Owen Jnr, Farmer AT. Primary adrenocortical nodular dysplasia: a rare cause of Cushing's syndrome. J Clin Endocrinol 1967;27:1255-63.

- Ruder HJ, Loriaux DL, Lipsett MB. Severe osteopenia in young adults associated with Cushing's syndrome due to micronodular adrenal disease. J Clin Endocrinol Metab 1974;39:1138-47.

- Studzinski GP, Hay DCF, Symington T. Observations on the weight of the human adrenal gland and effect of preparations of corticotrophin of different purity in the weight and morphology of the human adrenal gland. J Clin Endocrinol Metab 1963;23:248-54.

- Klevit HD, Campbell RA, Blair HR, Bongiovanni AM. Cushing's syndrome with nodular adrenal hyperplasia in infancy. $J$ Pediatr 1966;68:912-20.

- Donaldson MDC, Grant DB, O'Hare MJ, Shackleton CHL. Familial congenital Cushing's syndrome due to bilateral nodular adrenal hyperplasia. Clin Endocrinol 1981;14:519-26.

${ }^{7}$ Symington T. Functional pathology of the human adrenal gland. Edinburgh and London: Livingstone, 1969. 
- Sabatini DD, De Robertis EDP. Submicroscopic study of the pituitary action in the adrenocortex of the rat. Endocrinology 1962;70:390-406.

- Anderson DC, Child DF, Sutcliffe CH, Buckley CH, Davies D, Longson D. Cushing's syndrome, nodular adrenal hyperplasia and virilising carcinoma. Clin Endocrinol 1978;9:1-14.

${ }^{10}$ Salmon TN, Zwemer RL. A study of the life history of corticoadrenal gland cells of the rat by means of trypan blue injections. Anat Record 1941;80:421-9.

${ }^{11}$ Wright NA. Cell proliferation in the prepubertal male rat adrenal cortex; an autoradiographic study. $J$ Endocrinol 1971;49:599-609.
${ }^{12}$ Bennett HS. The life history and secretion of the cells of the adrenal cortex in the cat. Am J Anat 1940;67:151-227.

${ }^{23}$ Skelton FR. Adrenal regeneration and adrenal regeneration hypertension. Physiol Rev 1959;39:162-82.

Requests for reprints to: Dr PS Hasleton, Consultant Pathologist, Wythenshawe Hospital, Southmoor Road, Manchester M23 9LT, England. 